\title{
Altitude, Immigration and Suicide Rates: A Study from Turkey
}

\author{
Salih Selek \\ Department of Psychiatry, Faculty of Medicine, Istanbul Medeniyet University, Istanbul, Turkey
}

\begin{abstract}
Objective To investigate the altitude, immigration and suicide rates association in Turkey.
Methods Suicide and immigration rates of 81 provinces and their elevation data were obtained.

Results There were not significant correlations between country elevation, immigration and mean suicide rate.

Conclusion The findings of this study points out that altitude related hypoxia and suicide association may not be generalized and further research will be needed to clarify the effects of altitude on suicide rates.

Psychiatry Investig 2013;10:89-91
\end{abstract}

Key Words Altitude, Suicide rate, Immigration, Turkey.

\section{INTRODUCTION}

Suicide, the conscious act of self induced annihilation, is among the three leading causes of death among those middle aged people in several countries which is complex with psychological, social, biological, cultural and environmental factors involved. ${ }^{1}$ The term suicide refers to the completed suicide events in this paper. An understanding of the epidemiologic patterns of suicide is important for prevention; early recognition and finding at-risk individuals may prevent their action. ${ }^{2}$ In Turkey, suicide rate resulted with death is 3.51 per 100.000 in 2009. ${ }^{1}$ Rate of suicide attempts are unclear. Despite lower official suicide rates in Turkey, suicide is believed to be a major health problem that is underrated. ${ }^{2}$ Suicide studies related with immigration are also few in Turkey. For example, a database search with "suicide AND immigration" revealed 3 results in national academic network databases (ULAKBIM). Previous epidemiologic studies have demonstrated geographic variations in suicide patterns even after adjustment for gender, age and race. ${ }^{5,6}$ Researchers suggested that differences in availability of psychiatric services, rural isolation, and even geographic characteristics such as sunlight exposure and latitude may have interfered with the findings. ${ }^{7.8}$ Thus, several sociodemographic

Received: September 24, 2011 Revised: January 18, 2012

Accepted: September 27, 2012 Available online: January 25, 2013

$\triangle$ Correspondence: Salih Selek, MD

Department of Psychiatry, Faculty of Medicine, Istanbul Medeniyet University, 34700 Istanbul, Turkey

Tel: +90216-566 40 00, Fax: +90216-602 28 00, E-mail: drselek@yahoo.com

(a) This is an Open Access article distributed under the terms of the Creative Commons Attribution Non-Commercial License (http://creativecommons.org/licenses/by$\mathrm{nc} / 3.0$ ) which permits unrestricted non-commercial use, distribution, and reproduction in any medium, provided the original work is properly cited. characteristics are believed to be related with suicide rate. In addition, recent studies found a correlation between altitude and suicide rates in U.S.A. and South Korea. ${ }^{6}$ Hypoxia and several other mechanisms have been proposed to explain the relationship between suicide and high altitude. ${ }^{9}$

Immigration, the change of residence by any means, may influence the mental health status of individuals as well. ${ }^{10}$ In the early stage, shortly after arriving in the new place, immigrants are faced with new difficulties. Thus, immigrants may experience depression and anxiety which is related with suicidal behavior. ${ }^{11}$

Turkey is a country between Asia and Europe, and has a variable geography with many mountainous areas with 70 million populations. With the economic development and several other issues, there has been immigration from villages and small towns to high income bigger cities. ${ }^{12}$ A potential relation between immigration and suicide rates has been proposed in local researches. ${ }^{13}$ Turkish Stastical Institute collects the data of immigration movements and completed suicides every year and publishes as a book. This information is open to public and can be used with reference. ${ }^{14}$ Although the suicide rate is low in Turkey (3.51 in \%000), the impact of altitude and immigration on suicide need to be investigated in low suicide rated countries as well for generalization of the findings. ${ }^{14}$ Immigration and high altitude are two independent terms covered in this paper and the study does not focus on the interplay of these variables. In this study, evaluation of the association between immigration and suicide \& altitude and suicide in Turkey is aimed. 


\section{METHODS}

Suicide and immigration data was obtained from Turkish Statistical Institute (TSI). Suicide rates of 81 provinces in 2007 and 2008 and mean rate of two years were used. ${ }^{14}$ Since 2008, data related to suicide events occurring in permanent residence where the police is responsible have been started to take from The General Police Headquarters and from Gendarme (Rural Police) in rural areas. For every single suicide occurring, a "Suicide Statistics Form" was filled out by the police and sent to the office of the governor in provinces and districts. At the end of every month, governors' offices sent these forms to the Turkish Statistical Institute and data entry of suicide statistics forms was done by the Institute itself. ${ }^{14}$ Suicide rate was defined as "the number of suicides per thousand population in a given year". Immigration rates were obtained from the same source. Net immigration rate (NIR) is estimated by total immigration minus total emigration of a province. Elevation data were obtained from provinces' official web sites (i.e. province_name.gov.tr). In order to check the altitude, Google Earth 5.0 and construction corporations' data were used.

Pearson's correlation coefficients were computed to investigate the association.

\section{RESULTS}

Mean suicide rates were shown on Table 1. Median altitude was 726 meters with minimum $1 \mathrm{~m}$ and maximum $1890 \mathrm{~m} .53$ provinces were labeled as emigrated provinces and 28 provinces were labeled as immigrated provinces according to the net immigration rate (NIR). The sum of NIR of overall Turkey is 0 . Absolute value of NIR is 429,29 in Turkey. ${ }^{13}$ There were not significant correlations between country elevation and mean suicide rate, 2007 rates 2008 rates in Turkey $(r=-0.09, n=$ $81, \mathrm{p}=0.425 ; \mathrm{r}=-0.10, \mathrm{n}=81, \mathrm{p}=0.372$ and $\mathrm{r}=-0.06, \mathrm{n}=81, \mathrm{p}=$ 0.608 respectively) (Figure 1 ). There were no significant correlation between NIR and suicide rates, either $(r=0.042, n=81$, $\mathrm{p}=0.781$ and $\mathrm{r}=0.22, \mathrm{n}=81, \mathrm{p}=0.848$ respectively).

\section{DISCUSSION}

We did not found any association between altitude and suicide. The analysis of suicide data and county altitude in South Korea and USA showed a strong association between suicide rate and altitude (for S. Korea $\mathrm{r}=0.39$ ) in a previous study. ${ }^{6} \mathrm{Cul}-$ tural factors are known to influence suicide rates. ${ }^{15}$ The risk factors may vary among the countries as well. ${ }^{16}$ A recent study showed that suicide victims at high and low altitudes differ significantly by multiple demographic, psychiatric, and suicide characteristics; these factors, rather than hypoxia or altitude
Table 1. Mean suicide rates of immigrated and emigrated provinces per 100,000

\begin{tabular}{lcc}
\hline & $\begin{array}{c}\text { Immigrated } \\
\text { provinces }(\mathrm{N}=28)\end{array}$ & $\begin{array}{c}\text { Emigrated } \\
\text { provinces }(\mathrm{N}=53)\end{array}$ \\
\hline Mean Suicide Rate (2007) & $4.74 \pm 2.63$ & $4.23 \pm 1.77$ \\
Mean Suicide Rate (2008) & $4.69 \pm 2.36$ & $4.41 \pm 1.58$ \\
\hline
\end{tabular}

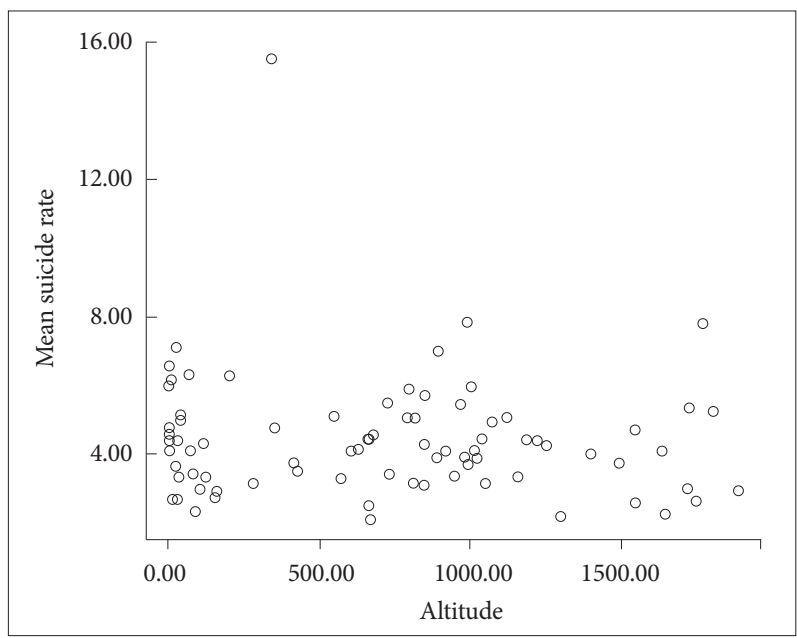

Figure 1. Scatter plot of the mean suicide rate and the altitude.

itself, may explain increased suicide rates at high altitude. ${ }^{5,17}$ Therefore, it is more likely that other factors like lower socioeconomic status may interfere with the results in Kim's Study. Within cultural context, high immigration rates to the industrialized provinces which have relatively low altitude and a relatively conservative nature of the high places might interfere with the results in Turkey. In addition, mean suicide rate is low (3.97 in \%000) in Turkey. ${ }^{13}$ Therefore, it may be difficult to draw a conclusion with the low rate.

We did not found any association between immigration and suicide, either. In a local study with a small sample size, immigration to Istanbul (most populated city in Turkey) was found to be associated with suicide rates and this finding was believed to be related when facilities were poor and lack of social services and social support, remote areas perhaps, and also geographical characteristics. ${ }^{12}$ Immigration is also found to be associated with trauma and therefore suicide rates. ${ }^{13}$ However, studies with positive findings mainly focused on international immigration. National immigration without enforcement may not yield similar findings with international immigration. Since immigration may have long term effects it may influence the suicide rates after a few years. Thus, developing mental disorders which may lead to suicide may take time. Immigration rate may be affected by transhumance (also for touristic purpose) which is frequently seen in Turkey.

The findings of this study points out that altitude related hypoxia and suicide association may not be generalized and fur- 
ther research will be needed to clarify the effects of altitude on suicide rates. This study has several limitations. The suicide and immigration rates are raw data obtained from TSI. Especially immigration rates show the displacement between provinces. It may not reflect the heterogeneity of the immigration effect. However, suicide studies are not adequate in Turkey especially in the eastern part. ${ }^{15}$ Further studies are needed to draw a conclusion.

\section{REFERENCES}

1. WHO. Suicide Prevention (SUPRE). Geneva: World Health Organization; 2011.

2. Satcher D. The Surgeon General's Call to Action to Prevent Suicide. Washington, DC: US Public Health Service; 1999.

3. Institute of Statistics. Suicide Statistics 2010. Ankara: Turkish Stattistical Institute; 2010.

4. Altindag A, Ozdemir B, Yanik M. Suicide with firearms in Sanliurfa. Anadolu Psikiyatri Dergisi 2005;6:240-244.

5. Betz ME, Valley MA, Lowenstein SR, Hedegaard H, Thomas D, Stallones L, et al. Elevated suicide rates at high altitude: sociodemographic and health issues may be to blame. Suicide Life Threat Behav 2011;41: 562-573.

6. Kim N, Mickelson JB, Brenner BE, Haws CA, Yurgelun-Todd DA, Renshaw PF. Altitude, gun ownership, rural areas, and suicide. Am J Psychiatry 2011;168:49-54.
7. Hemenway D, Miller M. Association of rates of household handgun ownership, lifetime mail or depression, and serious suicidal thoughts with rates of suicide across US census regions. Inj Prev 2002;8:313-316.

8. Terao T, Soeda S, Yoshimura R, Nakamura J, Iwata N. Effect of latitude on suicide rates in Japan. Lancet 2002;360:1892.

9. Haws CA, Gray DD, Yurgelun-Todd DA, Moskos M, Meyer LJ, Renshaw PF. The possible effect of altitude on regional variation in suicide rates. Med Hypotheses 2009;73:587-590.

10. Epelbaum C, Taylor ER, Dekleva K. Immigration trauma, substance abuse, and suicide. Harv Rev Psychiatry 2010;18:304-313.

11. Murphy EJ, Mahalingam R. Perceived congruence between expectations and outcomes: implications for mental health among Caribbean immigrants. Am J Orthopsychiatry 2006;76:120-127.

12. Ekici G, Savas HA, Citak S. Intihar riskini artıran psikososyal etmenler. Anadolu Psikiyatri Dergisi 2001;2:204-212.

13. Alptekin K, Duyan V, Demirel S. Adıyaman'da intihar girişimleri. Anadolu Psikiyatri Dergisi 2006;7:150-156.

14. Institute of Statistics. Suicide Statistics 2008. Ankara: Turkish Statistical Institute; 2009.

15. Foster RP. When immigration is trauma: guidelines for the individual and family clinician. Am J Orthopsychiatry 2001;71:153-170.

16. Yilmaz AT, Riecher-Rössler A. Attempted suicides in immigrants from Turkey: a comparison with Swiss suicide attempters. Psychopathology 2012;45:366-373.

17. Lester D. Suicide and homicide rates: their relationship to latitude and longitude and to the weather. Suicide Life Threat Behav 1986;16:356359. 